\title{
Coalition of National Health Education Organizations
}

\author{
Ellen M. Capwell \\ Otterbein College
}

\begin{abstract}
The Coalition of National Health Education Organizations (CNHEO), established in 1972, currently has a membership of ten professional health education organizations. It exists to advance the profession of health education and to foster communication, collaboration and action on issues important to health and health education. Recent accomplishments include two invitational conferences to assess the status of health education and set goals and recommendations for the 21st century, Health Education Advocacy Summit, Health Education Advocate web site, Code of Ethics for the Health Education Profession, Standard Occupational Classification of "health educator" by the federal government, and collaboration to promote National Health Education Week. Information can be found at the CNHEO website, http://www.hsc.usf.edu/CFH/cnheo/.
\end{abstract}

(C) 2004 Californian Journal of Health Promotion. All rights reserved.

Keywords: CNHEO, coalition, health education, health professions

The profession of health education is somewhat unique in that no one professional organization represents all health educators. With at least ten such organizations those outside of the profession sometimes become confused. The Coalition of National Health Education Organizations (CNHEO) is not yet another organization for individual health educators, but rather a federation of professional organizations dedicated to advancing the profession of health education and to communicating, collaborating, and acting on issues of importance to health and health education.

Professional Health Education organizations are the members of the CNHEO. Each provides a Delegate and Alternate to represent the organization. These representatives facilitate an exchange of information between their organization and the CNHEO. Different organizations assume lead responsibility for carrying out selected activities. The CNHEO currently consists of the following ten professional organizations:
- American Academy of Health Behavior ( $\underline{\mathrm{AAHB}})$

- American Association for Health Education (AAHE)

- American College Health Association, Health Education Section ( $\underline{\text { ACHA) }}$

- American Public Health Association - Public Health Education \& Health Promotion Section (APHA-PHEHP)

- American Public Health Association - School Health Education \& Services Section (APHASHES)

- American School Health Association (새A)

- Association of State and Territorial Directors of Health Promotion and Public Health Education (ASTDHPPHE), now referred to as Directors of Health Promotion and Education (DHPE)

- Eta Sigma Gamma (ESG)

- Society for Public Health Education (SOPHE)

- Society of State Directors for Health, Physical Education, and Recreation (SSDHPER)

The two most recent additions were Eta Sigma Gamma (1999) and the American Academy of Health Behavior (2003). Information and links to each membership organization can be found on the CNHEO website,. The primary requirements for membership are that an 
organization be national in scope and have health promotion / health education as a key element in its mission statement.

The CNHEO's roots go back to April, 1971, when the Executive Council of the School Health Division of the American Association for Health, Physical Education and Recreation approved a motion to study the feasibility of a federation of national health education organizations. Supported by Kimberly Clark Corporation, Metropolitan Life Insurance Company, and Association-Sterling Films, representatives of seven national health education organizations met to explore the feasibility of such a group. The appointment, in September 1971, of the President's Committee on Health Education created an environment that was supportive of establishing the CNHEO. Following drafting of a "Working Agreement," in December, 1971, and a meeting of the chief elected officers of the member organizations, in February 1972, the "Working Agreement" was approved and the CNHEO established on March 1, 1972 (Cauffman, 1982).

Despite the fact that the CNHEO currently functions with no paid staff or permanent location, it has strengthened communication among member organizations and their members, as well as with others who interact with the health education profession. The CNHEO carries on business by means of e-mail communication, monthly conference calls and periodic face-to-face meetings during member organization conferences. Through these means it has made significant progress in addressing its purposes and priorities.

A priority for the CNHEO in recent years has been the development of a shared vision and strategic plan for the health education profession. The CNHEO has sponsored two invitational meetings to assess the status of health education and to set future goals and recommendations. The 1995 forum, sponsored by the CNHEO and the National Commission for Health Education Credentialing (NCHEC), identified six focal areas for the health education profession. These included Professional Preparation, Quality Assurance, Research,
Advocacy, Promoting the Profession, and Dynamic / Contemporary Practice. Progress toward accomplishment of goals in these focal areas was documented in the publication, "The Health Education Profession in the Twenty-First Century: A Progress Report 1995-2001” (CNHEO, 2001). The 2002 forum, sponsored by CNHEO with support from the Centers for Disease Control \& Prevention, the American Cancer Society, ToucanEd, and the Rollins School of Public Health at Emory University, identified and prioritized recommendations for the profession in five focal areas. These were: Creating Synergy; Advocacy; Conducting, Translating, and Disseminating Research into Dynamic and Contemporary Practice; Professional Preparation \& Development and Quality Assurance; and Promoting and Marketing the Profession. This forum also provided an opportunity for leaders of CNHEO organizations to make commitments to take the lead or assist in addressing selected recommendations, or to indicate that they were already addressing selected recommendations or already had plans to do so (CNHEO, 2003b). Two areas in which CNHEO committees are already progressing toward accomplishment of recommendations are Creating synergy, and Promoting and Marketing the Profession. In an effort to keep the profession informed of individual organization's progress toward addressing the 21st Century recommendations, panel presentations were held at the annual conferences of both SOPHE and APHA during Fall 2003.

Education and advocacy for policies and programs that are supportive of healthy behaviors as well as healthy communities are also priorities for the CNHEO. In response to these priorities, the CNHEO has sponsored the Health Education Advocacy Summit annually in Washington, DC since 1998. The Summit provides an opportunity for representatives from each organization to participate in health issue updates, advocacy training and visits to key members of Congress. In 2002, the CNHEO established the "Health Education Advocate" website to provide a central, timely source of advocacy information related to health education and health promotion. (Health Education 
Advocate, 2004). Additionally, the CNHEO writes letters of support and testimony regarding issues of concern to the entire profession.

The CNHEO also collaborates on health education issues common to all member organizations. A major accomplishment in 1999 was establishment of the Code of Ethics for the Health Education Profession. Prior to this time different variations of codes of ethics existed within individual organizations. Through collaboration, these were folded together into the document that is now available on the CNHEO website. Historical information and an ordering form to obtain hard copies are also available on the website (CNHEO, 2003a). The CNHEO has also been represented on collaborative projects related to health education credentialing. Two current initiatives in which the CNHEO is participating are the Competency Update Project (CUP) and the Health Education Accreditation Task Force.

Increasing the understanding and visibility of the health education profession and its member organizations is another priority of the CNHEO. In 1998 health education professionals were mobilized to obtain passage of the Standard Occupational Classification of "health educator" by the Department of Labor, Bureau of Labor
Statistics (2002). This was significant because it marked the first time that the federal government began collecting employment data on health educators as a distinct occupation. CNHEO member organizations also collaborate with the National Center for Health Education to promote National Health Education Week held annually in October. This fosters consumer education about important public health issues and health education.

The actions described above represent the recent accomplishments of the CNHEO. Additional historical and operational information can be found at the CNHEO website and in the "Coalition of National Health Education Organizations Facts" brochure, soon to be available at the website. The CNHEO serves important functions, beyond what any individual health education professional organization can do at this time. The CNHEO does not seek to compete with individual professional organizations, each with its special perspective on health education, but rather to foster communication and action on issues of common interest to all of the member organizations. Through this communication and collaboration the profession of health education, as well as the impact of health education and health promotion practice, will be strengthened.

\section{References}

Cauffman, J. G. (1982). A history of the Coalition of National Health Education Organizations: Its first ten years and future directions. The Eta Sigma Gamma Monograph Series, 1(2).

Coalition of National Health Education Organizations (CNHEO). (2001). The health education profession in the twenty-first century progress report 1995-2001. Retrieved February 21, 2004, from http://www.hsc.usf.edu/CFH/cnheo/21st century.htm

Coalition of National Health Education Organizations (CNHEO). (2003a). Retrieved January 3, 2004 from http://www.hsc.usf.edu/CFH/cnheo/ethics.htm

Coalition of National Health Education Organizations (CNHEO). (2003b). Coalition of National Health Education Organizations' second invitational conference: Improving the nation's health through health education - a vision for the 21st century conference proceedings. Retrieved January 2, 2004, from http://www.hsc.usf.edu/CFH/cnheo/21st_century.htm

Health Education Advocate. (2004). Home page. Retrieved January 2, 2004, from http://healtheducationadvocate.org/mission.htm

US Department of Labor, Bureau of Labor Statistics. (2002). List of soc occupations, 21-0000 community and social services occupations, 21-1091 health educators. Retrieved January 3, 2004, from http://stats.bls.gov/oes/2002/oes stru.htm 


\section{Acknowledgements}

Appreciation is expressed to the CNHEO Delegates, Alternates and other organization representatives for their review and comments; and to the individuals, agencies and entities that made possible several of the CNHEO accomplishments. These include National Commission for Health Education Credentialing, Centers for Disease Control \& Prevention, Comprehensive Health Education Foundation, American Cancer Society, ToucanEd, Rollins School of Public Health at Emory University, and many more.

Author Information

Ellen M. Capwell, PhD, CHES

Department of Health and Physical Education

Otterbein College

One Otterbein College

Westerville, $\mathrm{OH} 43081$

E-Mail: ecapwell@otterbein.edu

Dr. Capwell is the Coordinator of the Coalition of National Health Education Organizations. 